\title{
The effects of fatigue on instep kick performance in soccer
}

\author{
Bekir MEHTAP, Sukru Serdar BALCI
}

Faculty of Sport Sciences, Selcuk University, Konya, Turkey.

This Study was summarized from master thesis and presented as a poster ar $13^{\text {th }}$ International Sports Sciences Congress in Selcuk University (7-9 Novemver 2014)

Address correspondence to B. Mehtap, e mail: bekirmehtap@selcuk.edu.tr

\begin{abstract}
This study was applied to investigate the effects of fatigue on instep kick performance in soccer. Seven male soccer players participated in this research. Each had a minimum 6 years of soccer playing experience. The age was (mean \pm SD) $22.85 \pm 1.57$ years, height $178.14 \pm 3.08 \mathrm{~cm}$, weight $69.35 \pm 3.71 \mathrm{~kg}$, body mass index $21.86 \pm 1.25 \mathrm{~kg} / \mathrm{m}^{2}$ and maxVO 2 values were $59.14 \pm 4.77$ $\mathrm{ml} / \mathrm{kg} / \mathrm{min}$ of subjects. The high intensity endurance protocol selected to be used in the present study has been previously applied to simulate soccer field conditions to occur fatigue on subjects. The subjects performed 5 instep kicks from the $16 \mathrm{~m}$ distance to the goal targets prior to, in the middle and after the implementation of a 90 min intermittent exercise protocol. Analysis of the sprint times taking a part in an exercise protocol, the significant difference was found (P<0.01). While there was an increase on sprint times, after the multiple comparison the significant difference was came out between the first and the last parts of the test protocol $(\mathrm{P}<0.05)$. During the exercise, when the average heart rate of subjects was compared according to the parts; there was significant differences with the first and third parts between the second and last parts $(\mathrm{P}<0.01)$. The lactate levels of subjects were increased throughout the exercise application. The results indicated that the lactate values were also significantly higher compared with the pre-fatigue values $(\mathrm{P}<0.01)$. The decrease was occurred on instep kick performance performed in accordance with F-Marc shooting dead ball test of all subject in the middle and after of the exercise protocol. The present results suggest that the fatigue affects the soccer kick performance. While the kicks apart the parts was compared there is a significant decreasing was observed. It can say that the fatigue affects the success of the kick.
\end{abstract}

Keywords: Fatigue, instep kick, soccer.

\section{INTRODUCTION}

Type of exercise in soccer is intermittent and changes occur in aerobic or anaerobic activity in every 4-6 seconds. An international soccer player performs about 1350 activities containing 220 highspeed running during a game (23). In addition to runs, soccer players perform activities in which different energy systems are used such as dribbling, intervention by sliding, head shots and tackles during the games $(5,29)$. This situation shows that soccer players need both high-rate aerobic and anaerobic strength and capacity during the games. There is a need for an aerobic energy in rate of $75 \%$ of the maximal oxygen use capacity in average during the game. This information shows that there is a need for effort in anaerobic threshold load level during the soccer competition (25). Fatigue means that an individual cannot maintain the expected or required strength production. In other words, fatigue is defined as reduction in the maximal strength required for maintaining the exercise and accordingly decreases in the performance (28).
The research conducted shows that when work load increases, duration providing the continuity of strength presented gets shorter regardless of the type of exercise. Inability in presenting the strength required for a certain exercise is expressed as fatigue (11). At the end of fatigue, there is a need for a good recovery capacity in order to repeat the activities required for the performance. This is possible with having an aerobic endurance (a good anaerobic threshold). For these reasons, knowing fatigue and its mechanisms in the soccer is very important for protection and improvement of the performance. Sports scientists and experts have considered that fatigue is the most important factor limiting the human performance for a long time. They conduct studies in order to overcome the negative effects of fatigue on the performance by searching the incidence sources of it (6).

Studies conducted show that high intensity races, distances covered and also sprints are higher in the first half compared with second half $(4,23)$. This state may be an indicator of temporary fatigue which soccer players are exposed during the game. 
In a study performed, every 5 minutes of timeframes in the game were examined and according to data obtained; it was found that performances of soccer players decreased and it dropped below the average performance throughout the game in every 5 minutes of periods after the high intensity races in these timeframes where game intensity and tempo are increased (23). Findings acquired reveal that performances of soccer players decrease after the periods when game intensities increase as an indicator of fatigue and also as a result of natural variables which tactical and psychological factors may cause.

Technique for shooting the ball is the leading one among the features which soccer players should have for being successful in the soccer (32). Shooting is one of the basic offensive movements in the soccer and teams shooting at goal more will have more chance for scoring goal and winning the match. For this reason, development of instep shooting technique in the soccer is one of the most important objectives in the exercises to be applied on young players in substructures (17). Instep shooting technique is mostly used while shooting a goal to the goalpost (2). It is generally a hard shooting pattern made to region of the ball regarded as center with instep of the foot generally for goal shootings in low level. The most important feature of this shooting is to shoot to the target with the hardest part of the foot in hard, low and straight linear angle. Thus, shots made with instep shooting are able to go faster and minimize the time required for defensive players and goal keepers to react. This situation provides advantage for the shooting soccer player and increases the goal rate (3). However, this rate is decreasing with the effect of disorders in the technical skills together with fatigue. Hence, Apriantono et al. (3) stated that post-fatigue shooting performances decrease significantly compared with pre-fatigue performance in their study they examined the effect of fatigue on the shootings made by using the instep technique.

In this study, we aim to determine what kind of changes occur in shooting performance at the end of long-term and high-intensity fatigue protocol adapted to soccer ground conditions and to present new data to the literature in this regard.

\section{MATERIAL \& METHODS}

\section{Research Group}

This study was conducted on 7 male soccer players who played as a licenses soccer player for at least 6 years and completed substructure trainings in professional soccer team substructures. It was paid attention that if dominant feet of all of the subjects were their right feet. Having no injury and not having suffered from any injury before at least 6 months were determined as criteria. This study was performed with approval of Ethics Committee of School of Physical Education and Sports of Selcuk University.

\section{Determination of Maximal Oxygen Consumption}

20 meters of shuttle run test was applied for determination of $\mathrm{maxVO}_{2}$ values of subjects (19). Test practice contains continuous races made between 2 points in 20 meters of distance within the timeframe between recorded stimulant sounds, determined according to test protocol. Athletes warmed in such way containing 5 minutes of stretching movements prior to the test. Test practice started with stimulant sound when athlete was ready and completed when athlete could not reach the places determined for 2nd time or was exhausted and gave up the race voluntarily. Each athlete completed the test on non-slip ground and by using the same materials.

Data obtained were recorded in $\mathrm{ml} / \mathrm{kg} / \mathrm{m}$ for using in determination of race tempo in fatigue protocol.

\section{Fatigue Protocol}

In the study, Gleeson et al. (1998) adapted to ground conditions in soccer game and implemented long-term and high-intensity endurance protocol which constitutes a basis for the next studies conducted $(20,26)$. Fatigue protocol diagram is shown in Figure 1.

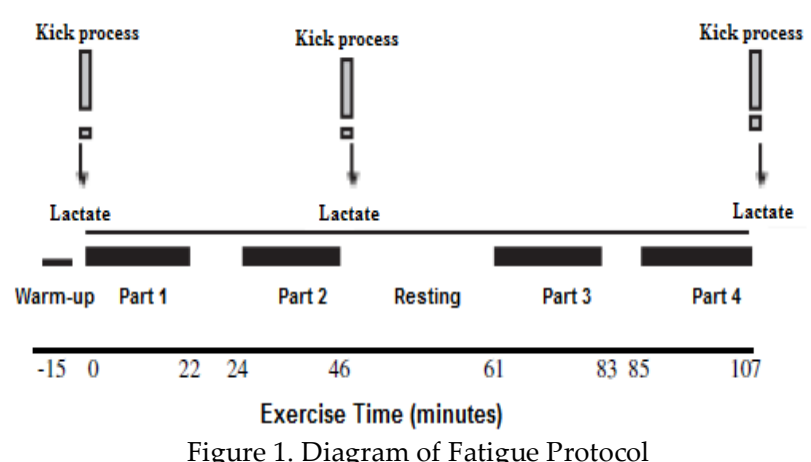

Test was performed on 20 meters of non-slip ground and outdoor. Participants completed 4 stages consisting of $12 \times 200$ meters during the test. Total race distance is consisted of 9600 meters. Each completed 200 meters of distances contain $60 \mathrm{~m}$ of walking, $15 \mathrm{~m}$ of sprint $(5 \mathrm{~m}$ of slowing and 
recovery walking), $60 \mathrm{~m}$ of jogging and $60 \mathrm{~m}$ of running activity (Figure 2).

Running and jogging tempo was regulated by Ramsbottom et al. (27) during the exercise, jogging tempo was regulated as $50-60 \%$ of max $\mathrm{VO}_{2}$ values of subjects and running tempo was regulated as 80$90 \%$ of these values according to shuttle number in each level and corresponding $\max \mathrm{VO}_{2}$ values table.

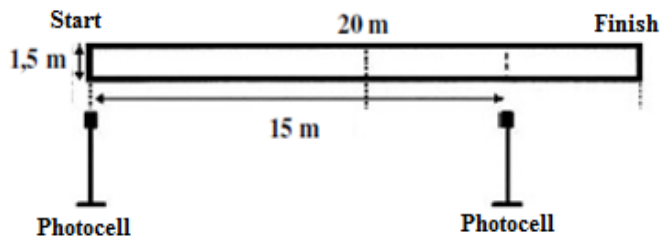

Figure 2. Test field of fatigue protocol

Subjects performed instep shootings, a shooting technique examined in the study, for 3 times; at the beginning of 1 st part and at the end of 2 nd and 4 th parts. Shootings in each part were repeated for 5 times in 30 seconds of intervals between each shooting. Shootings were performed by using soccer balls complying with game rules established by FIFA, in weight of $435 \mathrm{~g}(410-450 \mathrm{~g})$ and in atmosphere pressure of $0.6-1.1$.

Participants shoot according to principles of the highest speed and kicking. Shootings were performed towards standard soccer goalpost (length: $7.32 \mathrm{~m}$, width: $7.44 \mathrm{~m}$ ) from the point determined in $16 \mathrm{~m}$ of distance from mid-point of the goalpost in compliance with F-Marc Dead Ball Test criteria (30). According to test protocol; goalpost was divided into 6 equal areas. It was asked from soccer players to target primarily right and left top points. Each soccer player shoot by using right foot that is their dominant foot. Shots hitting right and left top points were scored as 3 points, shots hitting medium top region and posts as 1 point, shots hitting lower regions and going outside as pointless according to the shooting types.

\section{Recording of Sprint Periods}

15 meters of distance was determined within test raceway and sprint periods which subjects performed during the fatigue protocol were found by using photocell devices placed in two different places as starting and ending points between this distance and powered by light sensitivity. It was stated to athletes to run in the maximum speed between these two points. Each sprint period was recorded in second (s).

\section{Heart Rate Measurement}

Heart rates $(\mathrm{HR})$ of subjects were recorded in each 5 seconds of timeframes by using Polar RS-800 brand heart rate monitors. Subjects wore the device on wrists at the beginning of exercise practice and did not remove until the end of test protocol. Data recorded by heart rate monitor during the test period were transmitted to computer environment and HR values of athletes were examined.

\section{Lactate Analysis}

Blood samples were drawn from athletes' ear lobes just before the starting of test protocol (at the end of warming stage), just in the end of the first half period (2nd part) and just after the end of test (4th part) and analyzed by using lactate analyzer (Diaglobal GmbH, Berlin, Germany) in photometric method without waiting. Data obtained were recorded in $\mathrm{mmol} / \mathrm{L}$.

\section{Statistical Analysis}

Minimum, maximum, average and standard deviation values of subjects' physical characteristics were calculated and given. Sprint periods, heart rate and variation in lactate values were compared by performing single factor variant analysis in repeating measurements and Bonferroni correction. Differences at $\mathrm{P}<0.05$ level were accepted as significant.

\section{RESULTS}

Mean age, height, body weight and body mass index, body fat percentage of soccer players who participated into the study and minimum, maximum, average and standard deviation values of max $\mathrm{VO}_{2}$ values were given in Table 1.

Table 1. Age, height, weight, body mass index and $\mathrm{VO}_{2 \max }$ variables of subjects.

\begin{tabular}{lcccc}
\hline Variables & $\mathrm{N}$ & Min & Max & Mean \pm SD \\
\hline & 7 & 20 & 25 & $22.86 \pm 1.57$ \\
Age (year) & 7 & 173 & 181 & $178.14 \pm 3.08$ \\
Height $(\mathrm{cm})$ & 7 & 63 & 73.2 & $69.36 \pm 3.71$ \\
Weight $(\mathrm{kg})$ & 7 & 20.3 & 23.39 & $21.86 \pm 1.25$ \\
Body Mass Index $\left(\mathrm{kg} / \mathrm{m}^{2}\right)$ & 7 & 52 & 65 & $59.14 \pm 4.77$ \\
VO2max $(\mathrm{ml} / \mathrm{kg} / \mathrm{min}$ & & & &
\end{tabular}

Heart rates of subjects observed during the test practice are graphically seen in Figure 3. When HR values of subjects were examined, the highest HR value was obtained in 4 th part. While heart rate values of 1 st and 3rd parts were similar ( $P>0.05)$, they are significantly lower than HR values obtained 
in 2nd and 4th parts $(\mathrm{P}<0.05)$. Values of 2 nd and 4 th parts were identical $(\mathrm{P}>0.05)$.

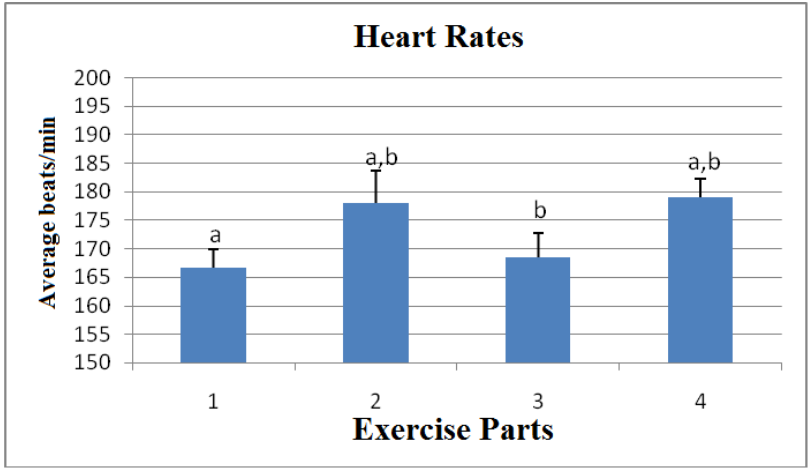

$\mathrm{a}, \mathrm{b}$ : Difference between averages bearing different letter in columns is important $(\mathrm{P}<0.05)$.

Figure 3. Average heart rates of subjects during the fatigue protocol.

Sprints performed repeatedly during the fatigue protocol implemented are given as graphic in Figure 3.

When sprint performances of subjects during the fatigue protocol were examined, while sprint performances obtained in 1st and 2nd parts were similar $(P>0.05)$, they were found as significantly lower than sprint performances obtained in 3rd and 4th parts $(\mathrm{P}<0.05)$. Sprint performances obtained in 3rd and 4th parts were determined as similar $(\mathrm{P}>0.05)$.

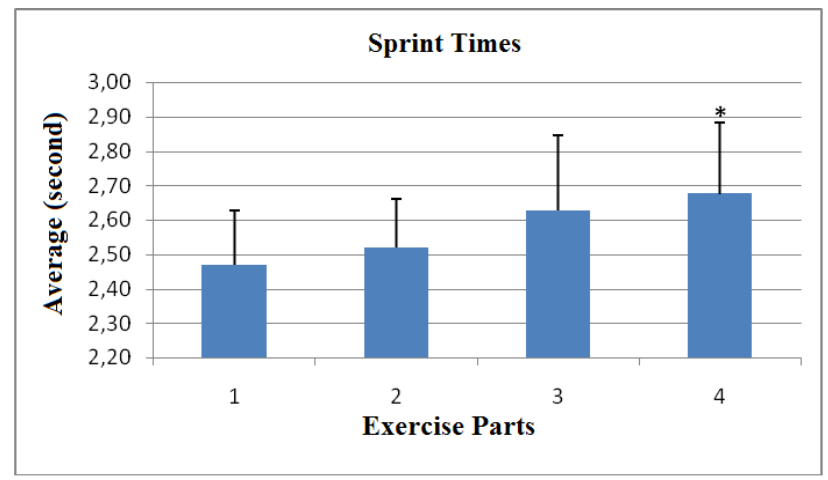

$a, b, c$ : Difference between averages bearing different letter in columns is important $(\mathrm{P}<0.05)$.

Figure 4. 15 meters of average sprint periods performed during the fatigue protocol.

Blood samples taken from subjects were examined and changes in lactate levels as well as fatigue were determined (Figure 4). According to data obtained, it was found that lactate values of subjects at the end of warming period (just before the starting of test protocol) were significantly lower than lactate values in the middle of the test (just after the end of 2 nd part). It was determined that lactate values at the end of the test (just after the end of 4 th part) were significantly higher than 1st part but significant lower than 2 nd part.

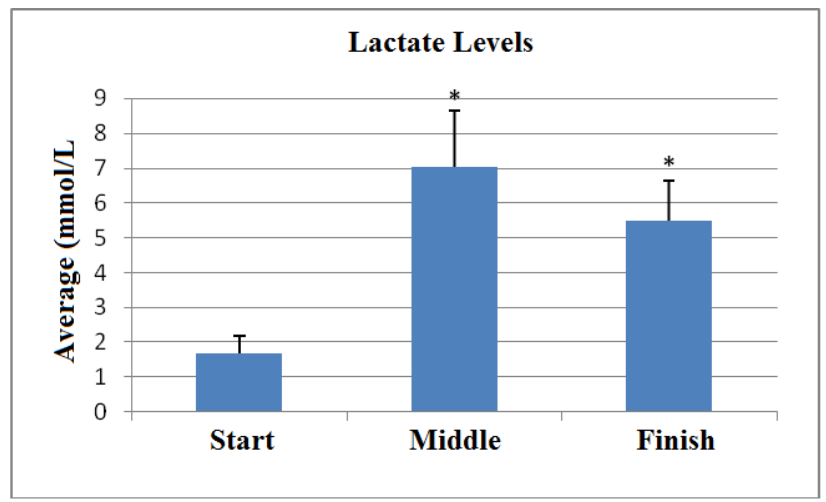

* shows the differences of the lactate values in the beginning, middle and end of the fatigue protocol.

Figure 5. Lactate Levels in the Test Protocol.

Points and success rates which subjects earned in instep shootings performed on the onset, midst and after the test in compliance with F-Marc dead ball test criteria are given in Table 2.

Table 2. Instep shooting scoring prior, midst and after the fatigue protocol.

\begin{tabular}{lcccccc}
\hline \multirow{2}{*}{ Fatigue } & \multicolumn{7}{c}{ Point } \\
\cline { 2 - 7 } & $\mathrm{N}$ & Min & Max & Mean \pm SD & Total & Success (\%) \\
\hline & & & & & & \\
Before & 7 & 4 & 10 & $7.14 \pm 2.19$ & 51 & 49 \\
Midst & 7 & 0 & 6 & $1.57 \pm 2.22$ & 11 & 10 \\
After & 7 & 1 & 4 & $3.14 \pm 1.07$ & 21 & 21 \\
& & & & & & \\
\hline
\end{tabular}

According to data obtained; a statistically significant difference was observed in instep shootings prior, midst and after the fatigue protocol $(\mathrm{P}<0.01)$. While differences in shootings were observed prior, midst and after the fatigue protocol $(\mathrm{P}<0.01)$, shootings made in the midst of and after the fatigue protocol are not statistically significant $(\mathrm{P}>0.05)$.

\section{DISCUSSION}

Long-term and high-intensity fatigue protocol which adapted to ground conditions in soccer game (12) and in which race tempo was determined by each individual's own maxVO2 value was applied onto the subjects in our study.

$\mathrm{MaxVO}_{2}$ values of the subjects participated into our study were determined as $59.14 \pm 4.77$ $\mathrm{ml} / \mathrm{kg} / \mathrm{min}$ on average. While Chamari et al. (9) determined $\mathrm{maxVO}_{2}$ values of soccer players as 61.1 $\pm 4.6 \mathrm{ml} / \mathrm{kg} / \mathrm{min}$ on average in their study, Stroyer et 
al. (33) reported that this value was $58.6 \pm 5.0$ $\mathrm{ml} / \mathrm{kg} / \mathrm{min}$ on average in Danish soccer players. Helgerud et al. (14) determined that $\operatorname{maxVO}_{2}$ values of young soccer players are $58.1 \pm 4.5 \mathrm{ml} / \mathrm{kg} / \mathrm{min}$ on average and that $\mathrm{maxVO}_{2}$ values of professional soccer players are $60.5 \pm 4.8 \mathrm{ml} / \mathrm{kg} / \mathrm{min}$ on average. Drust et al. (10) noted that $\mathrm{maxVO}_{2}$ values of 7 British universities soccer teams' players are $57.8 \pm$ $4.0 \mathrm{ml} / \mathrm{kg} / \mathrm{min}$ on average. In similar studies, while Impellizeri et al. (15) determined $m a x \mathrm{VO}_{2}$ values of soccer players playing in Italy as $57.4 \pm 4.0$ $\mathrm{ml} / \mathrm{kg} / \mathrm{min}$ on average, McMillan et al. (22) recorded this value as $63.4 \pm 5.6 \mathrm{ml} / \mathrm{kg} / \mathrm{min}$ on average. It is seen that $m a x \mathrm{VO}_{2}$ values obtained in the study we conducted are similar with other studies. This similarity in physical characteristics of subjects is important in terms of their eligibility and competency for the study.

During the fatigue protocol implemented in the study, heart rates of subjects were determined and changes occurred during the exercise were observed. In the review made accordingly, it was found that RH values obtained in 2nd and 4th parts of test significantly increased compared with $\mathrm{RH}$ values in 1st and 3rd parts.

Ali \& Farrally (1) recorded in their study conducted over $\mathrm{RH}$ values of soccer players during the game that heart rate of soccer players were 172 beat/min on average in semi-professional soccer players; 167 beat $/ \mathrm{min}$ on average in soccer players playing in university soccer team and 168 beat $/ \mathrm{min}$ on average in recreation group soccer players in 90 minutes of soccer game. McGregor et al. (20) found that $\mathrm{RH}$ values of athletes were $170 \pm 4$ beat $/ \mathrm{min}$ on average during 90 minutes' exercise protocol at high intensity and containing shuttle (20). While Strojer et al. (33) recorded average heart rate as 176 beat $/ \mathrm{min}$ in young soccer players, Mohr et al. (24) determined heart rate as $160-162$ beat $/ \mathrm{min}$ on average in soccer players playing in Denmark league. Kellis et al. (16) administered fatigue protocol implemented in our study, in their study; they suggested that HR values of athletes displayed significantly difference compared with rested heart rate values at the beginning of exercise.

Average HR values obtained following the test protocol implemented in our study show similarity with average hear rate values of soccer players during the game. This situation may be clarified as similarity in intensity of exercise implemented and competition tempo. On the other hand, it should be taken into account that there may be periods when high severe and activity intensity increased, periods when tempo is too low and resting period increased and hear rate may vary in the competition.

Sprint ability in the soccer is one of the factors which may affect the result in tackle and goal positions (31). Fatigue protocol applied in the study contains repetitive sprints. Subjects realized 15 meters of sprint for 48 times as 12 repetitions in each part during the test. General average of sprints performed during the process of test protocol was found as $2.57 \pm 0.30 \mathrm{~s}$. When parts of the test were examined; while a general increase was observed in sprint periods, a significant difference was found between sprint periods in 1st and 4th parts.

One of the methods of observing the fatigue composition is to determine the lactate level in the blood. In our study, when lactate levels of subject changing with fatigue were examined; there is a statistically significant difference in pre-test lactate values and post-test and at the end of test $(\mathrm{P}<0.01)$. This difference was observed as increase after and end of the test. This increase occurred reveals that desired fatigue formed. Lactate level of subjects observed in the process of fatigue protocol was determined as $4.74 \pm 1.08 \mathrm{mmol} / \mathrm{L}$ on average in the study. It was noted that lactate concentrations observed during the competition varied between 3-6 $\mathrm{mmol} / \mathrm{L}$ in soccer players $(5,12,25)$.

In the study where lactate levels of professional soccer players were examined during the competition, it was determined that lactate values of soccer players varied between $2.1-10.3 \mathrm{mmol} / \mathrm{L}$ on average in the first half and varied between 1.8-5.2 $\mathrm{mmol} / \mathrm{L}$ on average in the second half. It was found as $4.9 \mathrm{mmol} / \mathrm{L}$ on average in the end of first half and as $3.7 \mathrm{mmol} / \mathrm{L}$ on average in the end of second half. While decrease was observed in lactate levels towards the end of competition, it was stated that there was an important correlation between excess high intensity races and increase in lactate level $(\mathrm{P}<0.05)(4)$.

Again similarly, Capranica et al. (8) observed that lactate concentrations of young soccer players varied generally between $3.1-8.1 \mathrm{mmol} / \mathrm{L}$ on average during the game. In the same way, in the study where Brewer and Davis (7) examined lactate levels during the soccer match, they determined lactate values as $5.1 \mathrm{mmol} / \mathrm{L}$ on average in the end of first half and as $4.6 \mathrm{mmol} /$ Lon average in the end of second half. In the studies in which lactate levels of soccer players were examined, it was presented that a decrease was seen in lactate levels in the second half compared with the first half during the soccer 
match, in the above-mentioned studies. This decrease in lactate levels shows similarity with findings obtained in our study.

Mohr et al. (24) implemented repetitive sprint test on the soccer players before and after the both halves during the match and they noted that a significant decrease was seen in sprint performances of the soccer players before the second half compared with before the first half by the results they obtained, and also they found that a significant decrease was observed in values they obtained before and after the game in the same way.

Wragg et al. (34) determined that a significant difference emerged in sprint performances of athletes in repetitive sprint tests and that as repetition number increased, sprint periods increased. In another study; Krustrup et al. (18) stated that a decrease was seen in sprint performances at the end of first half and second half and after the periods when game intensity increased.

In the study, a statistically significant difference was observed in instep shooting performances before, in the midst and after the fatigue protocol, by the points earned in instep shootings by implementing F-Marc Dead Ball Test $(\mathrm{P}<0.01)$. While subjects show success in the rate of $51 \%$ by collecting the maximum point in shootings performed before the fatigue protocol, they showed success in rate of $10 \%$ by collecting 11 points in shootings performed in the midst of fatigue protocol and in rate of $21 \%$ by collecting 22 points after the fatigue protocol. While differences in the shootings were observed before, in the midst and after the fatigue protocol $(\mathrm{P}<0.01)$, shootings do not show statistically significance in the midst of and after the fatigue protocol $(\mathrm{P}>0.05)$. Decrease in points earned may be accepted as fatigue formation and decrease in instep shooting performance.

In conclusion, the present results suggest that the fatigue affects the soccer kick performance. While the kicks apart the parts was compared there is a significant decreasing was observed. It can say that the fatigue affects the success of the kick. . On the other hand the elements like ball velocity, leg strength, angular velocity and acceleration may affect the kick performance using instep soccer kick technique. For this reason the evaluation of these factors will provide an opportunity for examine multifaceted the kick performance in all respects.

\section{ACKNOWLEDGEMENTS}

This study was supported by The Scientific Research Projects Coordination Unit of Selcuk University (Project number: 10301002). None of the authors of this paper has a financial or personal relationship with other people or commercial identity mentioned in our paper that might lead to a conflict of interest for any of the authors.

\section{REFERENCES}

1. Ali A, Farraly M. Recording soccer players' heart rates during matches. J Sports Sci. 1991; 9: 183-9.

2. Apaydin A. Futbolda teknik ve taktik antrenman uygulamaları, Akmat Akınoğlu Matb. San.Tic.Ltd.Şti, Akmat, 1999.

3. Apriantono T, Nonome H, Yasuo I, Sano S. The effect of muscle fatique on instep kicking kinetics and kinematics in association soccer. J Sports Sci. 2006; 24(9), 951-60.

4. Bangsbo J, Norregard L, Thorsoe F. Activity profile of competition soccer. Can J Sports Sci. 1991; 16 (2): 110-16.

5. Bangsbo J. The physiology of soccer: with special reference to with soccer intense intermittent exercise. Acta Physiol Scand. 1994; 15 Suppl. 619: 1- 156.

6. Bompa T.O. Antrenman Kuramı ve Yöntemi, Bağırgan Yayınevi, Ankara, 1999.

7. Brewer J, Davis J. The female player. In: Ekblom B, editor. Soccer (Soccer). London: Blackwell Scientific. 1994; 95-99.

8. Capranica L, Tessitore A, Guidetti L, Figura F. Heart rate and match analysis in pre-pubescent soccer players. J Sport Sci. $2001 ; 19: 6,379-84$

9. Chamari K, Hachana Y, Ahmed YB, Galy O, Sghaier F, Chatard JC, HueO, Wissloff U. Field and laboratory testing in young elite soccer players. Br J Sports Med. 2004; 38 (2): 19196.

10. Drust B, Reilly $\mathrm{T}$, CableNT. Physiological responses to laboratory-based soccer-specific intermittent and continuous exercise. J Sports Sci. 2000; 18:11, 885-92.

11. Edwars RHT. Biochemical basis of fatigue in exercise performance, Human Kinetics, Champain, 1983.

12. Ekblom B. Applied physiology of soccer. Sports Med. 1986; 3 (1): 50-60.

13. Gleeson NP, Reilly T, Mercer TH, Rakowski S, Rees D. Influence of acute endurance activity and leg muscular and musculoskeletal performance. Med Sci Sports Exerc. 1998; 30, 596- 608.

14. Helgerud J, Engen LC, Wisloff U, Hoff J. Aerobic endurance training improves soccer performance, Med and Sci Sports Exerc. 2001; 33(11), 1925- 31.

15. Impellizzeri FM, Rampinini E, Coutts AJ, Sassi A, Marcora SM.Use of Rpe-Based training load in soccer. Med Sci Sports Exerc. 2004; 36: 6, 1042-47

16. Kellis E, Katis I, Vrabas S. Effects of an intermittent exercise fatigue protocol on biomechanics of soccer kick performance. Scand J Med Sci Sports. 2006; 16: 334-344. 
17. Kellis E, Katis A. Biomechanical characteristic and determinants of instep soccer kick. J Sport Sci Med. 2007; 6,154-165.

18. Krustrup P, Mohr M, Steenberg A, Bencke J, Kjaer M, Bangsbo J. Muscle and blood metabolites during a soccer game: Implications for sprint performance. Med Sci Sport Exerc. 2006;(38) 6 - 1165-74.

19. Leger LA, Lambert J (1982) A maximal multistage 20-m shuttle run test to predict VO2max, Eur J Applied Phys, 49, 112

20. McGregor SJ, Nicholas CW, Drawer S, Grayson A, Williams C. Metabolic responses to fluid ingestion during prolonged intermittent high intensity shuttle running. In Proceedings of the Fourth Science and Soccer Conference 1999; p54, Sydney: University of Technology.

21. McGregor SJ, Nicholas CW, Lakomy HKA, Williams C. The influence of intermittent high-intensity shuttle running and fluid ingestion on the performance of a soccer skill. J Sports Sci. 1999; 17:11, 895- 903.

22. McMillan K, Helgerud J, Macdonald R, Hoff J. Physiological adaptations to soccer specific endurance training in professional youth soccer players. Br J Sports Med. 2005; 39: 273- 277.

23. Mohr M, Krustrup P, Bangsbo. Match performance of high standart soccer players with a special reference to development of fatigue. J Sports Sci. 2003, 21(7), 519- 28.

24. Mohr M, Krustrup P, Nybo L, Nielsen JJ, Bangsbo J. Muscle temperature and sprint performance during soccer matches: benefical effect of re-warm-up at half-time. Scand J Med Sci Sports. 2004; 14 (3): 156- 62.
Mehtap and Balci 2015

25. Mohr M, Krustrup P, Bangsbo J. Fatigue in soccer: A brief review. J Sports Sci. 2005; 23: 6, 593- 599.

26. Nicholas G, Nuttall F, Williams C. The Loughborough intermittent shuttle test: a field test that simulates the activity pattern of soccer. J Sports Sci. 2000; 18: 97-104.

27. Ramsbottom R, Brewer J, Williams C. A Progressive shuttle run test to estimate maximal oxygen uptake. Brit J Sports Med. 1988; 22 (4): 141-144

28. Reilly T. Physiological aspects of soccer. Biology of Sports. 1994; 11, 3-20.

29. Reilly $T$, Energetics of high-intensity exercise (soccer) with particular reference to fatigue. J Sports Sci. 1997; 15: 3, 257- 63.

30. Rösch D, Hodgson R, Peterson L, Graf-Bauman T, Junge A, Chomiak J, Dvorak J. Assessment and Evaulation of Soccer Performance. Am J Sports Med. 2000; 28: s29.

31. Shephard RJ. Biology and medicine of soccer: An update,J Sports Sci. 1999; 17:10, 757-86.

32. Skogvang B, Peitersen B, Stanley-Kehş K. Soccer Today. Wadsworth/Thomson Learning, 2000; 5,20,28.

33. Strojer J, Hansen L, Hansen K. Physiological profile and activity pattern of young soccer players during match play. Med Sci Sports Exerc. 2004; 36 (1): 168- 74.

34. Wragg CB, Maxwell NS, Doust JH. Evaluation of the reliability and validity of a soccer-specific field test of repeated sprint ability. Eur J Appl Physiol. 2000; 83: 77-83. 